\title{
New treatment options in allergic rhinitis: patient considerations and the role of ciclesonide
}

\author{
F Braido \\ C Lagasio \\ IMG Piroddi \\ I Baiardini \\ GW Canonica
}

Allergy and Respiratory Diseases Department, University of Genoa, Italy
Correspondence: Walter Canonica Allergy and Respiratory Diseases Department, University of Genoa, Italy Email canonica@unige.it

\begin{abstract}
Allergic rhinitis (AR) is a chronic inflammatory respiratory disease affecting 5\%-50\% of the worldwide population and its prevalence is increasing (Herman 2007). In addition, AR is associated with asthma and other co-morbidities such as conjunctivitis and sinusitis. The main symptoms are nasal congestion, rhinorrea, sneezing, itching, and post-nasal drainage induced after allergen exposure by an IgE-mediated inflammation of the membranes lining the nose. AR is not a life-threatening disease, but it has been shown to have a significant impact on quality of life. The Allergic Rhinitis and its Impact on Asthma (ARIA) guidelines propose a classification of AR in intermittent and persistent, each graded as mild or moderate-severe, and provide a stepwise approach to the treatment. Inhaled steroids and antihistamine are the main tools in AR therapy but more safe and effective drugs are, however, needed. Inhaled steroid ciclesonide appears to be safe and effective.
\end{abstract}

Keywords: ciclesonide, allergic rhinitis, asthma, quality of life.

\section{The burden of allergic rhinitis: the patient's perspective}

Allergic rhinitis is a global health problem that causes major illness and disability worldwide. Allergic rhinitis (AR) affects social life, sleep, school, and work. The economic impact of allergic rhinitis is often underestimated because the disease does not induce elevated direct costs. The indirect costs are, however, substantial. It is now recognized that allergic rhinitis comprises more than the classical symptoms of sneezing, rhinorrhea, and nasal obstruction. It is associated with impairments in how patients function in day-to-day life (Kirmaz et al 2005). It has been known for a long time that having an allergic reaction causes significant fatigue and mood changes (Marshall et al 2002), some impairment of cognitive function (Marshall et al 2000; Kremer et al 2002), and depression and anxiety (Cuffel et al 1999; Bavbek et al 2002). Impairment of quality of life, and work and school performance is common, particularly in patients with severe symptoms. These aspects of qualityof-life impairment in AR should be quantified using two types of tools for HRQL assessment - generic and specific questionnaires (Meltzer 2001; Gerth Van Wijk 2003; Leong et al 2005).

\section{The available treatments}

Current pharmacology treatment for AR includes antihistamines, decongestants, anticholinergic agents, intranasal cromolyn, leukotriene modifiers and inhaled steroids. The Allergic Rhinitis and its Impact on Asthma (ARIA) guidelines (ARIA 2007) suggest a stepwise approach to AR treatment.

In mild intermittent rhinitis, oral or intranasal anti-H1, intranasal decongestants, and oral decongestants (not in children) are suggested. For moderate-severe intermittent rhinitis and mild persistent rhinitis, the suggested options (not in preferred order) 
are oral or intranasal anti-H1, oral anti-H1 + decongestant, intranasal CS, and chromones.

Moderate-severe persistent rhinitis requires intranasal CS as a first line treatment and, in case of major blockage, to add short course of oral CS or decongestant; if symptoms persists it should be useful to add oral anti-H1 ( \pm decongestants) and or ipratropium.

In accordance with ARIA guidelines (ARIA 2007), therapy with intranasal corticosteroid is recommended as first-line prescription treatment in all the cases of AR with the exception of mild intermittent. Specific immunotherapy represents the unique treatment able not only to improve symptoms and quality of life but also to modify the disease progression.

\section{The new treatment options Monoclonal anti-lgE antibody}

The recombinant, humanized, monoclonal anti-IgE antibody (omalizumab) forms complexes with free IgE, blocking its interaction with mast cells and basophils, and lowering (ARIA 2007) free IgE levels in the circulation (Holgate et al 2005). In a large pivotal trial, omalizumab decreased serum-free IgE levels and provided clinical benefit in a dose-dependent fashion in patients with seasonal allergic rhinitis (Linna et al 1992; Kaliner 2004). In adults and adolescents, omalizumab was found to decrease all nasal symptoms and to improve RQLQ in patients with rhinitis induced by birch and ragweed pollens as well as in those with sensitization to outdoor allergens (Adelroth et al 2001; Chervinsky et al 2003). Moreover, the treatment was safe and well tolerated (Berger et al 2003; Nayak et al 2003). The clinical benefit of treatment with omalizumab is associated with an anti-inflammatory effect on cellular markers in blood and nasal tissue (Plewako et al 2002; Bez et al 2004) as well as with a reduction in mast cell FceRI expression and function (Beck et al 2004). Omalizumab inhibits allergen challenge-induced nasal response (Hanf et al 2004).

\section{New inhaled steroids}

The relative efficiency of this treatment compared to H1antihistamines and intranasal glucocorticosteroids needs to be established and a thorough cost/efficacy analysis should be performed.

New inhaled steroids such as ciclesonide, appear to be promising. Ciclesonide, administered as an inactive parent compound that is metabolized by endogenous esterases in the upper and lower airways to the pharmacologically active metabolite, has shown to be effective, safe and, accordingly to once-daily administration, liked by patients.

\section{From available glucocorticosteroids to ciclesonide}

The goals of corticosteroid therapy are to maximize efficacy, minimize potential systemic adverse effects, and improve patient adherence. Factors that will potentially improve adherence to treatment and differentiate the inhaled corticosteroids are dosing, regimen, patient preference and costeffectiveness (Dupclay and Doyle 2002; Herman 2007).

The commercially available inhaled corticosteroids (ICS) for AR treatment are beclomethasone dipropionate (BDP), budesonide (BUD), flunisolide (FLU), fluticasone propionate (FP), mometasone furoate (MF), and triamcinolone acetonide (TA); most of these are also available as nasal sprays for the treatment of AR. There is no longer any doubt about their effectiveness in both asthma and rhinitis. Since ICS are widely used in both adults and children, the issue of safety and the risk/benefit ratio assumes a primary importance (Passalacqua et al 2000).

Treatment with glucocorticosteroids is the most efficacious medication for AR. The rationale for therapy using glucocorticosteroids can be summarized by their antiinflammatory action and by their capacity to reduce nasal mucosa hyperreactivity (ARIA 2007). These medications are effective in improving all symptoms caused by allergic reaction to nasal and bronchial mucosa. For this reason, ICS are the most appropriate first-line treatment, as they are more effective than any other treatment (Berger et al 2005; Bhatia et al 2005; ARIA 2007).

\section{Mechanism of action of ICS}

ICS are widely used and prescribed in both adults and children, usually in long-term treatments. Therefore, the safety of these drugs is of some importance for both general practitioners and specialists. The mechanism of action of glucocorticosteroids is directed to specific nuclear receptors, which induce and modulate the transcription of specific target genes. These genes encode for cytokines, lipocortin-1, endothelin, b-adrenoceptors, iNOS, endopeptidases, and so on. Several transcription factors are involved in this mechanism (CarsonJurica et al 1990; Munk et al 1990; Funder 1993; Barnes and Adcock 1993; Smith and Toft 1993; Barnes 1996). ICS exert their clinical and anti-inflammatory actions depending on a wide range of variables, including the status of the nasal and bronchial wall (Laitinen 1994; Barnes 1995; Kraft et al 1996), the pharmacodynamic-pharmacokinetic properties of the drug (Andersson and Ryrfeldt 1984; English et al 1994; Miller-Larson et al 1994; Lipworth 1995; Johnson 1996), the delivery system (Brown et al 1990; Selroos and Halme 1991; 
Smith et al 1995; Pedersen 1996), the patient's cooperation (Toogood et al 1984; Pedersen et al 1986; Lindgren et al 1987; Newman et al 1991), and the dosage regimen (Munch et al 1982; Pincus et al 1995; van Schayck et al 1995; Bernstein et al 2004). These factors also determine the severity and frequency of side-effects (Passalacqua et al 2000).

\section{Side-effects}

The occurrence and severity of these side-effects depend, as mentioned above, upon a large number of variables, including the characteristics of the drug (lipophilicity, pharmacokinetics, and pharmacodynamics) and the mode of administration (for example, dose, delivery system, coordination).

Intranasal corticosteroids are highly effective; nevertheless, they are not completely devoid of systemic effects. Thus, care has to be taken, especially in children, when prescribing long-term treatments.

According to the available controlled studies, some effects on the hypothalamic-pituitary-adrenal axis (HPAA) and bone metabolism are detectable with high doses of ICS. Indeed, the effects on the HPAA and bone metabolism are measurable only by means of biochemical parameters; their clinical significance is still unknown and probably extremely small compared to the benefit achieved. Exogenous steroids, through negative feedback, suppress corticotrophin secretion, thus leading to adrenal cortex atrophy and to subsequent decrease of cortisol secretion; in fact long-term treatment with oral corticosteroids may result in significant suppression of the HPAA. The free urinary cortisol over $24 \mathrm{~h}$ appears to be a practical and reliable index of HPAA interaction, since it provides a global evaluation of the adrenal function, and is not influenced by circadian changes in cortisol blood levels, but it is difficult to demonstrate its clinical counterpart and its clinical significance: in the controlled studies, no sign or symptom of adrenal failure was described.

Oral corticosteroids may induce osteoporosis and increase the risk of fractures in adult patients, reducing intestinal calcium absorption and enhancing its renal excretion; these actions result in compensatory secretion of parathormone, bone resorption, and increased activity of osteoclasts. Secondly, corticosteroids inhibit osteoblastic activity and the synthesis of osteocalcin. Thirdly, steroids reduce the synthesis of adrenal cortex-derived oestrogens. This last finding partly explains the increased risk of osteoporosis in postmenopausal women.

Although certain effects of ICS on bone metabolism are detectable, they are evident only by means of laboratory assessment, when high doses are used. In general, experimental evidence does not support an increased risk of osteoporosis or pathologic fractures in either adults or children. No change in bone density was detectable in adult patients taking ICS at high dosages (BUD or BDP $>800$ $\mathrm{mg}$ /day) for up to 18 months.

Some data suggest that high doses of ICS can affect short-term growth in children, but this effect is certainly less significant than that due to uncontrolled asthma. Growth retardation was seen only in children taking oral steroids. The available data suggest that short-term growth may be affected by high doses of ICS, but speed of growth and stature seem to depend strictly on the degree of asthma control. However this potential systemic side-effect imposes cautious use in children: the lowest effective dose must be used, and stature should be regularly monitored.

No significant effect on glucose metabolism has been shown for ICS, even with high doses. An increase in neutrophil counts in the peripheral blood of patients taking ICS has been noted. Some local side-effects have also been described. Since local application of corticosteroids may cause dermal atrophy, the possibility of mucosal atrophy and epistaxis by long-term use of intranasal steroids has been thoroughly investigated. Furthermore, the data indicated that some of the adverse events such as irritation, crusting, itching, and stinging may be due to the propellant used in older formulations rather than to the active drug.

Cutaneous side-effects may be of some relevance in the elderly, such as skin thinning and increased capillary fragility, especially in women, using high doses of ICS for long periods. Neurologic and ocular adverse events have to be considered anecdotal. In pregnant women, when indicated, ICS should be used at the lowest effective dose. BDP, for which more data are available, should be preferred; nevertheless, no actual teratogenicity in men has ever been reported. No specific study has been conducted on ICS and lactation (Passalacqua et al 2000).

\section{Ciclesonide}

Double blind, placebo-controlled studies on budesonide (Creticos et al 1998; Andersson et al 2000; Day et al 2000, 2001), fluticasone propionate (Nathan et al 1991; Dolovich et al 1994; LaForce et al 1994 Foresi et al 1996), mometasone fuorate (Bronsky et al 1997; Berkowitz et al 1999a, b; Gawchik et al 2003), and triamcinolone acetonide (Munk et al 1996; Settipane et al 2002) have shown that once-daily administration of these ICS are well tolerated and more effective than placebo in the treatment of seasonal AR (SAR) and perennial AR (PAR) (Herman 2007). 
Ciclesonide is a new-generation corticosteroid with previously demonstrated efficacy in the treatment of asthma when delivered through a metered-dose inhaler. Ciclesonide is also currently in clinical development as an intranasal formulation for use in the treatment of AR.

\section{Pharmacodynamics and pharmacokinetics}

The ciclesonide molecule has a chiral center in the acetal side chain. The two epimers of the compound are clearly different in their receptor affinities and metabolization rates. The R-epimer has a considerably higher binding affinity to the glucocorticoid receptor as compared to the S-epimer, and therefore only R-epimer is developed for clinical use (Schmidt et al 1999).

Ciclesonide is administered as an inactive parent compound that is metabolized by endogenous esterases in the upper and lower airways to the pharmacologically active metabolite desisobutyryl-ciclesonide (des-CIC). In vitro studies in rat lung have shown that esterification of des-CIC, working as a pool of active drug, may lead to durable antiinflammatory activity (Dietzel et al 2001; Nave et al 2005; Wingertzahm et al 2005; Ratner et al 2006a).

Advantages of on-site activation include targeted activation in the lung, minimal systemic adverse effects, and minimal oropharyngeal side effects (Ukena 2005).

Low oral bioavailability (oral bioavailability of des-CIC is approximately 1\%), high protein binding (99\%) and high hepatic clearance $(396 \mathrm{~L} / \mathrm{h})$ contribute to the favorable safety profile of ciclesonide.

\section{Clinical trials}

\section{Administration and dosage}

The intranasal administration of ciclesonide at recommended doses results in negligible serum concentrations of ciclesonide. However, the known active metabolite (desciclesonide) is detected in the serum of some patients after nasal inhalation of ciclesonide.

In healthy adults treated for 2 weeks with $50-800 \mu \mathrm{g}$ of ciclesonide nasal spray daily ( $\mathrm{n}=6$ in each treatment group), the peak serum concentrations of des-ciclesonide in all subjects were found to be below $30 \mathrm{pg} / \mathrm{mL}$. Among those treated with $800 \mu \mathrm{g}$ and $400 \mu \mathrm{g}$ daily, $100 \%$ and $67 \%$ had detectable levels of des-ciclesonide, respectively. With daily doses of $200 \mu \mathrm{g}$ or less, detectable serum levels of des-ciclesonide were not observed.

In pediatric subjects treated with $25-200 \mu \mathrm{g}$ of ciclesonide nasal spray daily, serum concentrations of des-ciclesonide were less than $45 \mathrm{pg} / \mathrm{mL}$, with the exception of one value of $64.5 \mathrm{pg} / \mathrm{mL}$. In a 12-week study, in children aged from 6 to 11 with perennial allergic rhinitis, des-ciclesonide was detected in $50 \%$ of subjects treated with $200 \mu \mathrm{g}$ and in 5\% of those treated with $100 \mu \mathrm{g}$ ciclesonide nasal spray daily. In a 6-week study, in children aged from 2 to 5 with perennial allergic rhinitis, des-ciclesonide was detected in $41 \%, 22 \%$, and $13 \%$ of subjects treated with $200 \mu \mathrm{g}, 100 \mu \mathrm{g}$, and $25 \mu \mathrm{g}$ ciclesonide nasal spray daily, respectively.

Following intravenous administration of $800 \mu \mathrm{g}$ of ciclesonide, the volumes of distribution of ciclesonide and des-ciclesonide were approximately $2.9 \mathrm{~L} / \mathrm{kg}$ and 12.1 $\mathrm{L} / \mathrm{kg}$, respectively. The percentage of ciclesonide and desciclesonide bound to human plasma proteins averaged $\geq 99 \%$ each, with $\leq 1 \%$ of unbound drug detected in the systemic circulation. Des-ciclesonide is not significantly bound to human transcortin.

Des-ciclesonide undergoes further metabolism in the liver to additional metabolites mainly by the cytochrome P450 (CYP) 3A4 isozyme and to a lesser extent by CYP 2D6. The full range of potentially active metabolites of ciclesonide has not been characterized. After intravenous administration of ${ }^{14} \mathrm{C}$-ciclesonide, $19.3 \%$ of the resulting radioactivity in the plasma is accounted for by ciclesonide or des-ciclesonide; the remainder may be a result of other, as yet, unidentified multiple metabolites.

Following intravenous administration of $800 \mu \mathrm{g}$ of ciclesonide, the clearance values of ciclesonide and desciclesonide were high (approximately $152 \mathrm{~L} / \mathrm{h}$ and $228 \mathrm{~L} / \mathrm{h}$, respectively). ${ }^{14} \mathrm{C}$-labeled ciclesonide was predominantly excreted via the feces after intravenous administration (66\%) indicating that excretion through bile is the major route of elimination. Approximately $20 \%$ or less of drug related radioactivity was excreted in the urine. The relative glucocorticoid receptor binding affinity of des-CIC is 100 -fold greater than that of ciclesonide. Des-ciclesonide has anti-inflammatory activity with affinity for the glucocorticoid receptor that is 120 times higher than the parent compound. (ALTANA Pharma 2006).

\section{Intranasal formulation}

Ciclesonide for intranasal use is formulated in a hypotonic suspension, which has been shown in preclinical in vivo models to provide enhanced tissue uptake when compared with a traditional isotonic formulation. In addition, the intranasal formulation of ciclesonide is preserved with potassium sorbate rather than benzalkonium chloride, which is used in many intranasal steroids (INSs). Benzalkonium chloride is believed to interfere with mucociliary transport and can lead 
to the development of hypersensitivity, rhinitis medicamentosa, and neutrophil dysfunction.

Furthermore, benzalkonium chloride has a bitter taste that might compromise patient adherence (Graf 1999; Bernstein 2000; Ratner et al 2006b).

\section{Efficacy and safety of ciclesonide}

The once-daily intranasal administration of $200 \mu \mathrm{g}$ of ciclesonide was shown to be effective for the treatment of seasonal AR, as demonstrated by a statistically significant improvement from baseline compared with that seen in the placebo group in the primary efficacy variable of the average of morning and evening reflective TNSSs (total nasal symptom score) over days 1-14. Interestingly, although inhaled steroid products are typically perceived as having the greatest effect on nasal congestion, this study demonstrated that ciclesonide nasal spray showed a similar magnitude of effect on all four components of the TNSS, namely nasal congestion, rhinorrhea, nasal itching, and sneezing. Although no direct head-to-head trials between ciclesonide and other products have been performed to date, the indirect comparison across studies suggests that the treatment-effect size observed between ciclesonide and placebo is larger than that generally seen with montelukast, as well as nonsedating oral histamines, such as desloratadine, in the treatment of seasonal allergic rhinitis (Salmun and Lorber 2002; Nasonex 2003). Additionally, the magnitude of effect observed in this study appears comparable with what had been previously demonstrated with mometasone in trials using a similar measurement scale (Dykewicz et al 2003).

The dosing posology was also assessed from the data of total nasal symptom score in another randomized, doubleblind, parallel-group, placebo-controlled, multicenter clinical trial (Ratner et al 2006b), which suggested that once-daily morning dosing is appropriate for ciclesonide nasal spray, and which could theoretically lead to increased compliance compared with drugs that are dosed twice or more daily.

In a multicenter, double-blind, randomized, placebocontrolled, 2-week safety and efficacy dose-ranging study, ciclesonide nasal spray (25-200 $\mu \mathrm{g} /$ day) was administered once daily for 14 days showing to be safe and effective in the treatment of SAR. Intranasal administration at doses of 100-200 $\mu \mathrm{g} /$ day was associated with dose-related improvements in nasal symptom relief compared with placebo and the $200 \mu \mathrm{g} /$ day dose was numerically superior to $100 \mu \mathrm{g} /$ day dose (Ratner et al 2006a).

Evidence supporting the $200 \mu \mathrm{g}$ /day dose of ciclesonide nasal spray as the starting and maximum doses in adult patients was obtained from a post hoc test demonstrating that there is a dose-dependent increase in efficacy and the $200 \mu \mathrm{g} /$ day dose of ciclesonide is the most effective dose studied for the amelioration of symptoms associated with SAR (Ratner et al 2006a).

Another study evaluated the efficacy and safety of intranasal ciclesonide, $200 \mu \mathrm{g}$ once-daily, for the treatment of perennial allergic rhinitis (PAR). In this double-blind, randomized, placebo-controlled study, patients with at least 2 years history of rhinitis received ciclesonide $(n=238)$ or placebo $(n=233)$ once daily for 6 weeks. In controlling daytime and nighttime, twice daily, nasal symptoms of PAR (runny nose, itchy nose, sneezing, and nasal congestion), ciclesonide was demonstrated to be superior to placebo. The comparable improvements in the morning and in the evening reflective TNSS observed in this study support the rationale for a once-daily dosing regimen of ciclesonide in the treatment of PAR.

Ciclesonide, $200 \mu \mathrm{g}$ once daily, was well tolerated in adult and adolescent patients with PAR and it was associated with a significant reduction in correlated total nasal symptoms. Moreover, the frequency of adverse events in patients in ciclesonide group was similar to that of placebo. Ciclesonide treatment improved one measure of quality of life and was delivered with the convenience of once-daily dosing (Meltzer et al 2007).

The efficacy and safety of ciclesonide in the treatment of allergic rhinitis have also been investigated in a double-blind, randomized, placebo-controlled, crossover trial involving 24 subjects who were symptom free at the time of the study. A dose of $200 \mu \mathrm{g} /$ nostril was administrated for 7 days. Subjective symptoms of obstruction, itching, and rhinorrhea improved from day 2 of treatment, and rhinal airflow showed significant improvement from day 5. Excellent tolerance at both local and systemic levels was seen (Meltzer and Derendorf 2006). These data confirmed the results of previous clinical trials (Ratner et al 2004; Nave et al 2006; Meltzer et al 2007).

Results from ciclesonide clinical trials in allergic rhinitis are summarized in Table 1.

\section{Ciclesonide and HPAA}

Several studies have evaluated the potential suppressive effects of ciclesonide on HPAA function by measuring both sensitive and clinically relevant markers.

In a placebo-controlled, randomized, double-blind, 4-period changeover equivalence study of healthy volunteers, ciclesonide (640 $\mu \mathrm{g} / \mathrm{day})$ was administered once daily, in the morning or evening, or half-dosed twice daily, to evaluate 
Table I Ciclesonide clinical trials in allergic rhinitis

\begin{tabular}{|c|c|c|c|c|c|c|}
\hline Author (year) & Disease & Method & Patients & Duration & Outcomes & Results \\
\hline Ratner (2006b) & SAR & DBPCR & 327 & 28 days & $\begin{array}{l}\text { Efficacy, safety, } \\
\text { tolerabily }\end{array}$ & $\begin{array}{l}\text { "Intranasal ciclesonide } \\
\text { was superior to placebo } \\
\text { in relieving nasal symp- } \\
\text { toms in[...]confirm the } \\
\text { dose range-finding study } \\
\text { and support the efficacy } \\
\text { of ciclesonide in AR" }\end{array}$ \\
\hline Nave (2006) & SAR & DBPCR & 48 & 14 days & $\begin{array}{l}\text { Efficacy, safety, } \\
\text { tolerabiliy }\end{array}$ & $\begin{array}{l}\text { "The low systemic } \\
\text { exposure and favorable } \\
\text { safety profile support } \\
\text { the continued clinical } \\
\text { development" }\end{array}$ \\
\hline Ratner (2006a) & SAR & DBPCR & 145 & 14 days & Efficacy, safety & $\begin{array}{l}\text { " } 200 \mu g \text { appears to } \\
\text { be the optimal dose } \\
\text { studied for reducing the } \\
\text { symptom of SAR wile } \\
\text { mantaining an acceptable } \\
\text { safety profile" }\end{array}$ \\
\hline Meltzer (2007) & PAR & DBPCR & 471 & 42 days & Efficacy, safety & $\begin{array}{l}\text { "Significant reductions } \\
\text { in nasal symptoms and } \\
\text { appociable improvements } \\
\text { in health quality of life. } \\
\text { Ciclesonide was well } \\
\text { tolerated" }\end{array}$ \\
\hline Schmidt (1999) & $A R$ & DBPCR & 24 & 14 days & $\begin{array}{l}\text { Efficacy, safety, } \\
\text { tolerabily }\end{array}$ & $\begin{array}{l}\text { "The treatment with } \\
\text { ciclesonide is effective, } \\
\text { without producing local } \\
\text { or systemic side effects" }\end{array}$ \\
\hline $\begin{array}{l}\text { ALTANA Pharma } \\
(2006)\end{array}$ & SAR PAR & 4DBPCR & 1524 in 3 trials & $\begin{array}{l}3 \text { trials: } 2-6 \text { weeks } \\
\text { I trial: I year }\end{array}$ & $\begin{array}{l}\text { Efficacy, safety, } \\
\text { tolerabily }\end{array}$ & $\begin{array}{l}\text { "The results showed that } \\
\text { patients treated with } \\
200 \mu g \text { once daily exhib- } \\
\text { ited statically significantly } \\
\text { greater decreases in total } \\
\text { nasal symptom scores } \\
\text { than placebo treated } \\
\text { patients. Measures of effi- } \\
\text { cacy were also generally } \\
\text { supportive" }\end{array}$ \\
\hline
\end{tabular}

Abbreviations: AR, allergic rhinitis; DBPCR, double blind, placebo-controlled, randomized trial; PAR, perennial allergic rhinitis; SAR, seasonal allergic rhinitis.

its effect on cortisol excrection and circadian serum cortisol rhythm. Patients were hospitalized after 6 days of ciclesonide treatment to measure 24-hour serum cortisol levels across the seventh day of treatment.

The 24-hour cortisol profiles obtained after ciclesonide treatment were equivalent to those observed in the placebo control group, because no significant difference was seen in cortisol amplitude and acrophase (time to maximum). These results suggest that ciclesonide at a dose of up to $640 \mu \mathrm{g} / \mathrm{day}$ does not disrupt cortisol production or the normal diurnal rhythm of endogenous cortisol secretion, regardless of the time of administration.
This lack of effect that ciclesonide has on HPAA function has been repeatedly demonstrated in several additional shortterm safety and efficacy trials and long-term safety studies at doses that are therapeutically effective.

Overall, the observations from these studies demonstrate that treatment with ciclesonide in adults appears to achieve comparable efficacy with a currently available ICS treatment while also reducing systemic activity, as evaluated by basal cortisol excretion on HPAA stimulation. Since all ICSs deposited in the lungs enter the systemic circulation at some stage in the drug's life-cycle, the lack of effect on HPAA function with ciclesonide may be due to its unique 
pharmacologic characteristics: the low levels of systemically available pharmacologically active desisobutyryl-ciclesonide, in addition to rapid elimination and low oral bioavailability, may account for the lack of clinically relevant effect that ciclesonide has on HPAA function, as evaluated by both basal cortisol concentration measurements and dynamic stimulation tests (Meltzer and Derendorf 2006).

\section{Adverse effects}

In a phase I, single center, randomized, double-blind, placebocontrolled, multiple-dose, modified sequential design study, healthy volunteers or asymptomatic subjects with a history of seasonal allergic rhinitis were randomized to receive ciclesonide or placebo via intranasal pump spray for 14 days. As expected, intranasal ciclesonide (50-800 $\mu \mathrm{g}$ /day) administration was generally safe and well tolerated in both healthy volunteers and asymptomatic subjects with SAR. An increase in the dose of ciclesonide did not correlate with an increase in adverse event frequency and the incidence of treatmentemergent adverse events was comparable between healthy volunteers and subjects with SAR. The data are consistent with earlier findings in a 7-day trial of ciclesonide nasal spray delivered via a pressurized metered-dose inahaler versus placebo in subjects with allergic rhinitis, wherein the frequency of treatment-emergent adverse events was low and no local or systemic side-effects were reported (Nave et al 2006).

A total of 134 treatment-emergent adverse events was reported by 41 participants (out of a total of 100 participants). The most common adverse effects were headache (11\%), fatigue $(7 \%)$, and rhinitis $(7 \%)$. The majority of adverse events (97\%) were mild in intensity. The frequency of adverse events was comparable among healthy volunteers and asymptomatic subjects with SAR. The most common adverse events considered by the investigator to be possibly or probably related to study medication were nose congestion, headache, and rhinorrhea. No adverse events were considered to be definitely related to the study medication. No serious adverse event was reported (Nave et al 2006).

\section{Conclusions}

Ciclesonide nasal spray provided substantial symptom relief, as measured by patients and physicians. Intranasal administration of ciclesonide was well tolerated, with an overall incidence rate of adverse events comparable with that of placebo. The demonstrated efficacy and favorable safety and tolerability profile of ciclesonide suggest that ciclesonide nasal spray is an effective treatment option for patients with AR (Ratner et al 2006b).
These findings, in conjunction with the observed clinical efficacy of ciclesonide, may suggest that ciclesonide has an improved therapeutic profile and safety compared with some other currently available ICS treatments and, therefore, the potential to ameliorate adherence rates and therapeutic outcomes (Meltzer and Derendorf 2006).

\section{Acknowledgments}

The authors thank ARMIA (Associazione Ricerca Malattie Immunologiche e Allergiche) for supporting the literature review. A special mention to Dr. Silvia Raco for the language revision.

\section{Disclosures}

The authors have no conflicts of interest to disclose.

\section{References}

Adelroth E, Rak S, Haahtela T, et al. 2001.Recombinant humanized mAb$\mathrm{E} 25$, an anti-IgE $\mathrm{mAb}$, in birch pollen-induced seasonal allergic rhinitis. J Allergy Clin Immunol, 106:253-9.

ALTANA Pharma. 2006. Ciclesonide nasal spray. Draft Labeling Text 1.14.1.3.

Andersson P, Ryrfeldt A. 1984. Biotransformation of the topical glucorticosteroids budesonide and beclomethasone 17,21 dipropionate in human liver and lung homogenate. J Pharm Pharmacol, 763:765-36.

Andersson M, Svensson C, Persson C, et al. 2000. Dose-dependent effects of budesonide aqueous nasal spray on symptoms in daily nasal allergen challenge model. Ann Allergy Asthma Immunol, 279:283-85.

[ARIA] Allergic Rhinitis and its Impact on Asthma guidelines. 2007. Accessed 31 Jan 2008. URL: http://www.whiar.org/.

Barnes PJ, Adcock I. 1993. Anti-inflammatory actions of steroids: molecular mechanism. Trends Pharmacol Sci, 436:441-14.

Barnes PJ. 1995. Inhaled glucocorticoids for asthma. $N$ Engl J Med, 332:868-75.

Barnes PJ .1996. Molecular mechanism of steroid action in asthma. J Allergy Clin Immunol, 159:168-97.

Bavbek S, Kumbasar H, Tugcu H, et al. 2002. Psychological status of patients with seasonal and perennial allergic rhinitis. J Investig Allergol Clin Immunol, 12:204-10.

Beck LA, Marcotte GV, MacGlashan D, et al. 2004. Omalizumab-induced reductions in mast cell Fcepsilon RI expression and function. J Allergy Clin Immunol, 114:527-30.

Berger WE, Nayak AS, Staudinger HW. 2005. Mometasone furoate improves congestion in patients with moderate to-severe seasonal allergic rhinitis. Ann Pharmacother, 39:1984-9.

Berger W, Gupta N, McAlary M, et al. 2003. Evaluation of long-term safety of the anti-IgE antibody, omalizumab, in children with allergic asthma. Ann Allergy Asthma Immunol, 91:182-8.

Berkowitz RB, Roberson S, Zora J, et al. 1999a. Mometasone furoate nasal spray is rapidly effective in the treatment of seasonal allergic rhinitis in an outdoor (park), acute exposure setting. Allergy Asthma Proc, 167:172-20.a.

Berkowitz RB, Bernstein DI, LaForce C, et al. 1999b. Onset of action of mometasone furoate nasal spray (NASONEX) in seasonal allergic rhinitis. Allergy, 64:69-54.b.

Bernstein IL. 2000. Is the use of benzalkonium chloride as a preservative fornasal formulations a safety concern? A cautionary note based on compromisedmucociliary transport. J Allergy Clin Immunol, 105:39-44.

Bernstein DI, Levy AL, Hampel FC, et al. 2004. Treatment with intranasal fluticasone propionate significantly improves ocular symptoms in patients with seasonal allergic rhinitis. Clin Exp Allergy, 34:952-7. 
Bez C, Schubert R, Kopp M, et al. 2004. Effect of anti-immunoglobulin E on nasal inflammation in patients with seasonal allergic rhinoconjunctivitis. Clin Exp Allergy, 34:1079-85.

Bhatia S, Baroody FM, deTineo M, et al. 2005. Increased nasal airflow with budesonide compared with desloratadine during the allergy season. Arch Otolaryngol Head Neck Surg, 131:223-8.

Bronsky EA, Aaronson DW, Berkowitz RB, et al. 1997. Dose ranging study of mometasone furoate (nasonex) in seasonal allergic rhinitis. Ann Allergy Asthma Immunol, 51:56-79.

Brown PH, Blundell G, Greening AP, et al. 1990. DO large volume spacer device reduce the systemic effects of hight dose inhaled corticosteroids? Thorax, 736:739-95.

Carson-Jurica MA, Schrader WT, O’Malley BW. 1990. Steroid receptor family: structure and function. Endocr Rev, 201:210-11.

Chervinsky P, Casale T, Townley R, et al. 2003. Omalizumab, an anti-IgE antibody, in the treatment of adults and adolescents with perennial allergic rhinitis. Ann Allergy Asthma Immunol, 91:160-7.

Creticos P, Fireman P, Settipane G, et al.1998. Intranasal budesonide aqueous pump spray (Rhinocort aqua) for the treatment of seasonal allergic rhinitis. Rhinocort Aqua Study Group. Allergy Asthma Proc, 285:294-19.

Cuffel B, Wamboldt M, Borish L, et al.1999. Economic consequences of comorbid depression, anxiety, and allergic rhinitis. Psychosomatics, 40:491-6.

Day JH, Briscoe MP, Rateiro E, et al. 2000. Onset of action of intranasal budesonide (Rhinocort Aqua) in seasonal allergic rhinitis studied in a controlled exposure model. J Allergy Clin Immunol, 105(3):489-94.

Day JH, Briscoe MP, Rateiro E, et al. 2001. A single-dose of budesonide $64 \mu \mathrm{g}$ (Rhinocort Aqua) is effective for severe allergic rhinitis symptoms in a controlled pollen setting. J Allergy Clin Immunol, S313-107.

Dietzel K, ENgelstatter R, Keller A. 2001. Ciclesonide: an on site- activated steroid. Prog Respir Res, 31:91-3.

Dolovich J, Wong AG, Chodirker WB, et al. 1994. Multicenter trial of fluticasone propionate aqueous nasal spray in ragweed allergic rhinitis. Ann Allergy, 147:153-73.

Dupclay L Jr, Doyle J. 2002. Assessment of intranasal corticosteroid use in allergic rhinitis: Benefits, costa, and patient preferences. Am J Manag Care, S335:S340-8.

Dykewicz MS, Kaiser HB, Nathan RA, et al. 2003. Fluticasone proprionate aqueous nasal spray improves nasal symptoms of seasonal allergic rhinitis when used as needed. Ann Allergy Asthma Immunol, 41:48-91.

English AF, Neate MS, Quint DJ et al.1994. Biological activities of some steroids used in asthma. Am J Respir Crit Care Med, (Suppl 4): A212-149.

Foresi A, Pelucchi A, Gherson G, et al. 1996. Once daily intranasal fluticasone propinate (200 micrograms) reduces nasal symptoms and inflammation but also attenuates the increase in bronchial responsiveness during the pollen season in allergic rhinitis. J Allergy Clin Immunol, 98(2):274-82

Funder JW. 1993. Mineralcorticosteroids, glucocorticosteroids, receptors and response elements. Science, 1132:1136-259.

Gawchik S, Goldstein S, Prenner B, et al. 2003. Relief of cough and nasal symptoms associated with allergic rhinitis by mometasone furoate nasal spray. Ann Allergy Asthma Immunol, 416:421-90.

Gerth Van Wijk R. 2003. Quality of life, should we bother? Allergy, 58:284-6.

Graf P. 1999. Adverse effects of benzalkonium chloride on the nasal mucosa: allergic rhinitis and rhinitis medicamentosa. Clin Ther, 21:1749-55.

Hanf G, Noga O, O'Connor A, et al. 2004. Omalizumab inhibits allergen challenge-induced nasal response. Eur Respir J, 23:414-8.

Herman H. 2007. One-daily administration of intranasal corticosteroids for allergic rhinitis: A comparative review of efficacy, safety, patient preference, and cost. Am J Rhinol, 70:79-21.

Holgate S, Casale T, Wenzel S, et al. 2005. The anti-inflammatory effects of omalizumab confirm the central role of IgE in allergic inflammation. J Allergy Clin Immunol, 115:459-65.
Johnson M. 1996. Pharmacodynamics and pharmacokinetics of inhaled glucocorticoids. J Allergy Clin Immunol, 169:176-97.

Kaliner MA. 2004. Omalizumab and the treatment of allergic rhinitis. Curr Allergy Asthma Rep, 4:237-44.

Kirmaz C, Aydemir O, Bayrak P, et al. 2005. Sexual dysfunction in patients with allergic rhinoconjunctivitis. Ann Allergy Asthma Immunol, 95:525-9.

Kraft M, Djukanovic M, Wilson R, et al. 1996. Alveolar tissue inflammation in asthma. Am J Respir Crit Care Med, 1505:1510-154.

Kremer B, den Hartog HM, Jolles J. 2002. Relationship between allergic rhinitis, disturbed cognitive functions and psychological well-being. Clin Exp Allergy, 32:1310-5.

LaForce CF, Dockhorn RJ, Findlay SR, et al. 1994. Fluticasone prorpionate: an effective alternative treatment for seasonal allergic rhinitis in adults and adolescents. J Fam Pract, 145:152-38.

Laitinen A, Laitinen LA. 1994. Arway morphology:epithelium/basement membrane. Am J Respir Crit Care Med, S14:S17-150.

Leong KP, Yeak SC, Saurajen AS, et al. 2005. Why generic and diseasespecific quality of-life instruments should be used together for the evaluation of patients with persistent allergic rhinitis. Clin Exp Allergy, 35:288-98.

Lipworth BJ. 1995. New prospectives on inhaled drug delivery and systemic bioactivity. Thorax, 105:110-10.

Lindgren S, Bake B, Larsson S. 1987. Clinical consequences of inadequate inhalation technique in asthma therapy. Eur J Respir Dis, 70:93-8.

Linna O, Kokkonen J, Lukin M. 1992. A 10-year prognosis for childhood allergic rhinitis. Acta Paediatr, 81:100-2.

Marshall PS, O'Hara C, Steinberg P. 2000. Effects of seasonal allergic rhinitis on selected cognitive abilities. Ann Allergy Asthma Immunol, 84:403-10

Marshall PS, O'Hara C, Steinberg P. 2002. Effects of seasonal allergic rhinitis on fatigue levels and mood. Psychosom Med, 64:684-91.

Meltzer EO. 2001. Quality of life in adults and children with allergic rhinitis. J Allergy Clin Immunol, 108(1 Suppl):S45-53.

Meltzer EO, Derendorf H. 2006. The systemic safety of inhaleted corticosteroid therapy: a focus on ciclesonide. Ann Allergy Asthma Immunol, 97:149-57.

Meltzer EO, Kunjibettu S, Hall N, et al. 2007. Efficay and safety of ciclesonide, $200 \mu \mathrm{g}$ once daily, for the treatment of perennial allergic rhinitis. Ann Allergy Asthma Immunol, 175:181-98.

Miller-Larson A, Mattson H, Ohlsson D, et al. 1994. Prolonged release from the arway tissue of glucocorticoids budesonide and fluticasone prrpionate as compared to beclomethasone dipropionate and hydrocortisone. Am J Respir Crit Care Med, A466-148.

Munch EP, Taudorf E, Weeke B. 1982. Dose frequency in the treatment of asthmatics with inhaled topical steroid. Eur J Respir Dis, $122: 143-53$

Munk A, Mendel DB, Smith LI et al. 1990. Glucocorticoid receptor and action. Am Rev Respir Dis, S2:S10-141.

Munk ZM, LaForce C, Furst JA, et al. 1996. Efficacy and safety of triamcinolone acetonide aqueous nasal spray in patients with seasonal allergic rhinitis. Ann Allergy Asthma Immunol, 277:281-77.

Nasonex (mometasone furoate monohydrate) [package insert]. 2003. Kenilworth (NJ): Schering Corp.

Nathan RA, Bronsky EA, Fireman P, et al. 1991. Once daily fluticasone propionate aqueous nasal spray is an effective treatment for seasonal allergic rhinitis. Ann Allergy, 332:338-67.

Nave R, Meyer W, Fuhst R, et al. 2005 Formation of fatty acid conjiugates of ciclesonide active metabolite in the rat lung after4 week inhalation of ciclesonide. Pulm Pharmacol Ther, 390:396-18.

Nave R, Wingertzahn MA, Brookman S, et al. 2006. Safety, tolerability, and exposure of Ciclesonide nasal spray in healthy and asymptomatic subjets with seasonal allergic rhinitis. J Clin Pharmacol, 461:467-46.

Nayak A, Casale T, Miller SD, et al. 2003 Tolerability of retreatment with omalizumab, a recombinant humanized monoclonal anti-IgE antibody, during a second ragweed pollen season in patients with seasonal allergic rhinitis. Allergy Asthma Proc, 24:323-9. 
Newman SP, Weisz AWB, Talaee N, et al. 1991. Improvement of drug delivery with a breath actuated pressurised aerosol for patients with poor inhaler technique. Thorax, 712:716-46.

Passalacqua G, Albano M, Canonica GW, et al. 2000. Inhaled and nasal corticosteroids: safety aspects. Allergy, 16:33-55

Pedersen S, Frost L, Arnfred T. 1986. Errors in inhalation technique and effciency in inhaler use in asthmatic children. Allergy, 118:123-41.

Pedersen S. 1996. Inhalers and nebulisers: which to choose and why. Respir Med, 69:77-90.

Pincus DJ, Szetler SJ, Ackerson LN, et al. 1995. Chronotherapy of asthma with inhaled steroids: the effect of dosage timing on drug efÆcacy. J Allergy Clin Immunol, 1172:1178-95.

Plewako H, Arvidsson M, Petruson K, et al. 2002. The effect of omalizumab on nasal allergic inflammation. J Allergy Clin Immunol, 110:68-71.

Ratner PH, van Bavel JH, Hampel F, et al. 2004. Dose dependent effectiveness of ciclesonide nasal spray in the treatment of seasonal allergic rhinitis (SAR) [Abstract]. J Allergy Clin Immunol, S28-113.

Ratner PH, Wingertzahn MA, Van Bavel JH. 2006a. Effectiveness of ciclesonide nasal spray in the treatment of seasonal allergic rhinitis. Ann Allergy Asthma Immunol, 657:663.a-97.

Ratner PH, Wingertzahn MA, van Bavel JH, et al. 2006b. Efficacy and safety of ciclesonide nasal spray for the treatment of seasonal allergic rhinitis. J Allergy Clin Immunol, 118:1142-8.

Salmun LM, Lorber R. 2002. 24-hour efficacy of once-daily desloratadine therapy in patients with seasonal allergic rhinitis. BMC Fam Pract, $3: 14$
Schmidt BM, Timmer W, Georgens AC, et al. 1999. The new topical steroid ciclesonide is effective in the treatment of allergic rhinitis. $J$ Clinical Pharmacol, 1062:1069-39.

Selroos O, Halme M, 1991. Effect of a volumatic spacer and mouth rinsing on systemic absorption of inhaled corticosteroids from a metered dose inhaler and dry powder inhaler. Thorax, 891:894:46.

Settipane G, Korenblat PE, Winder J, et al. 1995. Triamcinolone acetonide aqueous nasal spray in patients with seasonal ragweed allergic rhinitis: A placebo - controlled, double blind study. Clin Ther, 252:263-2.

Smith DF, Toft DO. 1993. Steroid receptor and their associated proteins. Mol Endocrinol, 4:10-7.

Smith EC, Denyer J, Kendrick AH. 1995. Comparison of twenty-three nebulizer/compressor combinations for domiciliary use. Eur Respir J, 1214:1221-8.

Toogood JH, Baskerville J, Jennings B, et al.1984. Use of spacers to facilitate inhaled corticosteroid treatment of asthma. Am Rev Respir Dis, 723:729-129.

Ukena D. 2005. Ciclesonide. Pneumologie, 59:689-95.

van Schayck CP, van Den Broek PJJ, van Den Otter JJ, et al. 1995. Periodic treatment regimen with inhaled steroids in asthma or chronic obstructive pulmonary disease. JAMA, 161:164-274.

Wingertzahm M, Sato H, Nave R, et al. 2005. Uptake and activation of Ciclesonide (CIC) in hypotonic and isotonic suspension and the formation of fatty acid conjiugates of desisobutyryl-ciclesonide (des-CIC) in vivo in rabbit nasal mucosa. Paper presented at 23rd Annual Aspen Allergy Conference; July 26-30 Aspen. Colorado. 
